\title{
Differences in mitochondrial gene expression profiles, enzyme activities and myosin heavy chain types in yak versus bovine skeletal muscles
}

\author{
Y.Q. Lin' ${ }^{1}$ Y.O. Xu' ${ }^{1}$ Y. Yue', S.Y. Jin', Y. Qu' ${ }^{2}$, F. Dong' ${ }^{2}$ Y.P. Li $^{3}$ and \\ Y.C. Zheng ${ }^{1}$ \\ ${ }^{1}$ College of Life Science and Technology, \\ Southwest University for Nationalities, Chengdu, P.R. China \\ ${ }^{2}$ Science and Technology Bureau of Ganzi Prefecture, Kangding, P.R. China \\ ${ }^{3}$ Agricultural and Animal Husbandry Bureau of Jiulong County, \\ Sichuan, P.R. China \\ Corresponding author: Y.C. Zheng \\ E-mail: yucaizheng65@hotmail.com
}

Genet. Mol. Res. 11 (3): 2871-2877 (2012)

Received September 9, 2011

Accepted May 8, 2012

Published May 22, 2012

DOI http://dx.doi.org/10.4238/2012.May.22.3

\begin{abstract}
Hypoxia can affect energy metabolism. We examined gene expression and enzyme activity related to mitochondrial energy metabolism, as well as myosin heavy chain $(\mathrm{MyHC})$ types in yaks (Bos grunniens) living at high altitudes. Real-time quantitative PCR assays indicated that the yak has significantly lower levels of carnitine palmitoyltransferase $(C P T)$ mRNA in the biceps femoris and lower levels of uncoupling protein 3 (UCP3) mRNA in both biceps femoris and longissimus dorsi than in Yellow cattle. No significant differences between yak and Yellow cattle were observed in the activities of mitochondrial $\beta$-hydroxyacyl-CoA dehydrogenase, isocitrate dehydrogenase and cytochrome oxidase in the same muscles. Semiquantitative RT-PCR analysis showed that the MyHC 1 mRNA levels in yak biceps femoris was lower than in Yellow cattle. We conclude that the yak has significantly lower mRNA levels of $C P T, U C P 3$, and $M y H C 1$ in biceps femoris than in Yellow cattle, suggesting that the
\end{abstract}


yak biceps femoris has lower fatty acid oxidation capacity and greater glycolytic metabolic potential.

Key words: Carnitine palmitoyltransferase; Uncoupling protein; Myosin heavy chain; Hypoxia adaptation; Bos grunniens

\section{INTRODUCTION}

Mitochondria are the primary source of cellular energy and produce the majority of ATP used to drive life processes. Alteration of mitochondrial energy production may affect many events such as growth, feed efficiency and health of animals (Bottje and Carstens, 2009). There are studies showing that genes regulating metabolism and energy partitioning have the potential to influence economically important traits in farm animals (Sherman et al., 2008). Thus, mitochondrial genes involved in energy metabolism are potential candidate genes for economic traits.

Yak is the sole bovine species adapted to the hypoxic environment of Qinghai-Tibetan Plateau, and it is the major meat source for local Tibetan farmers. It is documented that muscle adaptation to hypoxia in humans involves a decrease in muscle oxidative capacity (Hoppeler et al., 2003), a change in oxidative muscle metabolism towards a higher dependence on carbohydrates as fuel, and reduction in intramyocellular lipid stores (Jurie et al., 2006). It has been reported that the intramuscular fat content in yak is lower than that of Yellow cattle (Cai and Wiener, 1995). Thus, we hypothesized that gene expressions and enzyme activities related to energy metabolism in yak mitochondria may differ from those of low latitude Yellow cattle, which may have a differential influence on muscle development. In this study, we compared the gene expression of mitochondrial carnitine palmitoyltransferase $(C P T)$, uncoupling protein 3 (UCP3), and activities of $\beta$-hydroxyacyl-CoA dehydrogenase (HOAD), isocitrate dehydrogenase (ISDH) and cytochrome oxidase (COX), as well as myosin heavy chain $(\mathrm{MyHC})$ types between yak and Yellow cattle muscles, to shed light on the correlation or interaction between environment, mitochondrial metabolism and muscle development.

\section{MATERIAL AND METHODS}

\section{Animals and sampling}

Muscle samples were taken from healthy male Jiulong yaks $(5.4 \pm 1.7$ years old, N $=8$ ) reared in Jiulong County of Sichuan Province, China. The experimental yaks grazed on natural pasture at an altitude of $3500 \mathrm{~m}$ without any feed supplementation. Thirty minutes after slaughter, a longissimus muscle sample was taken from each yak at the position between the last thoracic spine and the third lumbar spine of the right side of the carcass, and a biceps femoris sample was taken from corresponding individuals. Longissimus and biceps femoris muscles were also taken from eight steers (Chinese Yellow cattle, $4.8 \pm 0.9$ years old) reared at low altitude for comparison. All of the muscle samples were promptly frozen and stored at $-80^{\circ} \mathrm{C}$. This experiment was conducted according to the guidelines of Chinese government for the use of experimental animals and EC Directive 86/609/EEC for animal experiments. 


\section{Muscle enzyme activity assay}

Muscle activities of three enzymes, including HOAD, ISDH and COX, were assayed. Muscle extract preparation and enzyme activity analysis was carried out according to the methods of Jurie et al. (2006).

\section{mRNA level quantification}

The mRNA levels of $C P T$ and $U C P 3$ were quantified by real-time quantitative RTPCR using the $\beta$-actin gene as internal control. The primers were designed based on corresponding gene mRNA sequences in GenBank as listed in Table 1. Total RNA was extracted from muscle using the TRIzol reagent (Invitrogen, New Zealand). Purity and concentration of RNA was determined spectrophotometrically by measurement of UV absorbance at 260 and $280 \mathrm{~nm}$. For the assay, cDNA was synthesized by reverse transcription from $1 \mu \mathrm{g}$ total RNA in a 20- $\mu$ L final volume using 100 U Superscript II reverse transcription and $10 \mathrm{pmol}$ oligo(dT), as described in the manufacturer protocol. The amplification mixture contained $1 \mu \mathrm{L}$ RT reaction mix, $10 \mu \mathrm{L} 2 \mathrm{X} \mathrm{SYBR}{ }^{\circledR}$ Premix Ex Taq ${ }^{\mathrm{TM}}$ (TaKaRa, China), $0.5 \mu \mathrm{L} 10 \mu \mathrm{M}$ each primer and $\mathrm{ddH}_{2} \mathrm{O}$ to $20 \mu \mathrm{L}$. Reactions were run on a iCycler thermo cycler iQ5 (Bio-Rad), The PCR conditions were as follows: one cycle of $1 \mathrm{~min}$ at $95^{\circ} \mathrm{C} ; 45$ cycles of $30 \mathrm{~s}$ at $95^{\circ} \mathrm{C}, 30 \mathrm{~s}$ at $54^{\circ} \mathrm{C}$ and $30 \mathrm{~s}$ at $72^{\circ} \mathrm{C}$. The threshold cycle (CT) resulting from RT-PCR was analyzed using the $2^{-\Delta \Delta \mathrm{Ct}}$ method (Livak and Schmittgen, 2001).

\begin{tabular}{|c|c|c|c|c|}
\hline Gene & Primers & GenBank accession No. & Amplicon size (bp) & Annealing temperature $\left({ }^{\circ} \mathrm{C}\right)$ \\
\hline$\beta$-actin & $\begin{array}{l}\text { F: CATCCGCAAGGACCTCTAC } \\
\text { R: ATGCCAATCTCATCTCGTTTT }\end{array}$ & BT030480 & 340 & 54 \\
\hline$U C P 3$ & $\begin{array}{l}\text { F: ACCATCGCCAGAGAGGA } \\
\text { R: AGGGGCTGTGGTACTGG }\end{array}$ & NM_174210 & 268 & 54.3 \\
\hline$C P T$ & $\begin{array}{l}\text { F: AGTCTGGGCTGTCTGTGTCC } \\
\text { R: TGGGGGCAGTCTTCTCCT }\end{array}$ & GU230741 & 203 & 55.5 \\
\hline MyHC 1 & $\begin{array}{l}\text { F: GCTGAAAGCAGAGAGAGATTAT } \\
\text { R: CGTCAAAGGCGTTATCAGT }\end{array}$ & AB059400 & 185 & 51 \\
\hline MyHC $2 A$ & $\begin{array}{l}\text { F: CCATGATGACCCACTTGC } \\
\text { R: TCAGGATTGACTGATTCTCTCG }\end{array}$ & AB059398 & 255 & 55 \\
\hline MyHC $2 X$ & $\begin{array}{l}\text { F: TGTTCCTGTGGATGGTTGC } \\
\text { R: TTTGGGTTTCTGGAAGTTGTT }\end{array}$ & AB059399 & 398 & 54.4 \\
\hline
\end{tabular}

Semi-quantitative RT-PCR was employed to assay mRNA levels of three isoforms of $M y H C$ in yak and bovine muscles. PCR amplifications were performed under standard conditions: denaturation at $94^{\circ} \mathrm{C}$ for $2 \mathrm{~min}$, then 33 cycles of $94^{\circ} \mathrm{C}$ for $30 \mathrm{~s}, 51^{\circ} \mathrm{C}$ to $55^{\circ} \mathrm{C}$ (annealing temperature) for $30 \mathrm{~s}$ and $72^{\circ} \mathrm{C}$ for $1 \mathrm{~min}$. Primers were designed as shown in Table 1. PCR products were examined by electrophoresis on agarose gels, and the relative mRNA abundance was expressed as the ratio of intensity between the amplified bands of the target gene and $\beta$-actin gene.

\section{Statistical analysis}

Data were analyzed using Statistical Package for the Social Science (SPSS Inc., ver- 
sion 11.5). Values are reported as means $\pm \mathrm{SE}$, and the significance of differences was evaluated using the Student unpaired $t$-test with the level of significance level set at $\mathrm{P}<0.05$.

\section{RESULTS}

\section{Expression level of $C P T$ and $U C P 3$ in skeletal muscles}

Yak contained a significantly lower level of $C P T$ mRNA than Yellow cattle in biceps femoris $(\mathrm{P}<0.05)$ but not in longissimus dorsi (Table 2). Besides, biceps femoris contained a higher level of $C P T$ mRNA than did longissimus dorsi in both yak and Yellow cattle $(\mathrm{P}<$ 0.05). Compared to Yellow cattle, both biceps femoris and longissimus dorsi of yak exhibited a lower level of $U C P 3$ mRNA $(\mathrm{P}<0.05)$.

\begin{tabular}{|c|c|c|c|c|c|c|}
\hline \multirow[t]{2}{*}{ Gene } & \multicolumn{3}{|c|}{ Longissimus dorsi } & \multicolumn{3}{|c|}{ Biceps femoris } \\
\hline & Yak & Yellow cattle & $P$ & Yak & Yellow cattle & $P$ \\
\hline$C P T$ & $1.03 \pm 0.19$ & $1.94 \pm 0.32$ & 0.088 & $0.04 \pm 0.01^{*}$ & $1.04 \pm 0.21$ & 0.040 \\
\hline$U C P 3$ & $1.01 \pm 0.12 *$ & $2.63 \pm 0.34$ & 0.029 & $0.003 \pm 0.001 *$ & $1.04 \pm 0.19$ & 0.034 \\
\hline
\end{tabular}

$* \mathrm{P}<0.05$. Comparison was conducted between yak and Yellow cattle for the same type of muscle.

\section{Activities of HOAD, ICDH and COX in skeletal muscles}

Three enzymes involved in fatty acid oxidation, citric acid cycle and respiratory chain, respectively, were assayed. Biceps femoris contained higher activities of HOAD and COX and similar level of ICDH compared to longissimus dorsi in yak but not in Yellow cattle (Table 3). No significant difference in enzyme activities was observed in the same type muscles between yak and Yellow cattle.

Table 3. Enzyme activities in skeletal muscles of yak and Yellow cattle.

\begin{tabular}{lccc}
\hline Enzyme & Muscle type & Yak $(\mathrm{N}=11)$ & Yellow cattle $(\mathrm{N}=8)$ \\
\hline HOAD (U/g tissue) & LD & $0.61 \pm 0.09$ & $0.83 \pm 0.08$ \\
ISDH (U/g tissue) & BF & $1.17 \pm 0.21^{*}$ & $0.80 \pm 0.14$ \\
& LD & $0.12 \pm 0.02$ & $0.23 \pm 0.06$ \\
COX (U/g tissue) & BF & $0.18 \pm 0.04$ & $0.24 \pm 0.07$ \\
& LD & $13.30 \pm 0.99$ & $16.16 \pm 2.38$ \\
& BF & $25.06 \pm 2.33^{* *}$ & $18.68 \pm 2.96$ \\
\hline
\end{tabular}

*** Indicate that the difference in enzyme activity is significant between $\mathrm{LD}$ and $\mathrm{BF}$ at $\mathrm{P}<0.05$ and $\mathrm{P}<0.01$, respectively. $\mathrm{HOAD}=\beta$-hydroxyacyl-CoA dehydrogenase; $\mathrm{ISDH}=$ isocitrate dehydrogenase; $\mathrm{COX}=$ cytochrome oxidase; $\mathrm{LD}=$ longissimus dorsi; $\mathrm{BF}=$ biceps femoris.

\section{$M y H C$ type of yak skeletal muscles}

Semi-quantitative RT-PCR assay showed that the proportion of $M y H C$ mRNA level in 
yak biceps femoris was lower than that of Yellow cattle (Figure 1); however, yak and Yellow cattle showed similar proportions of $M y H C$ 1, MyHC $2 A$ and $M y H C 2 X$ mRNA in longissimus dorci.

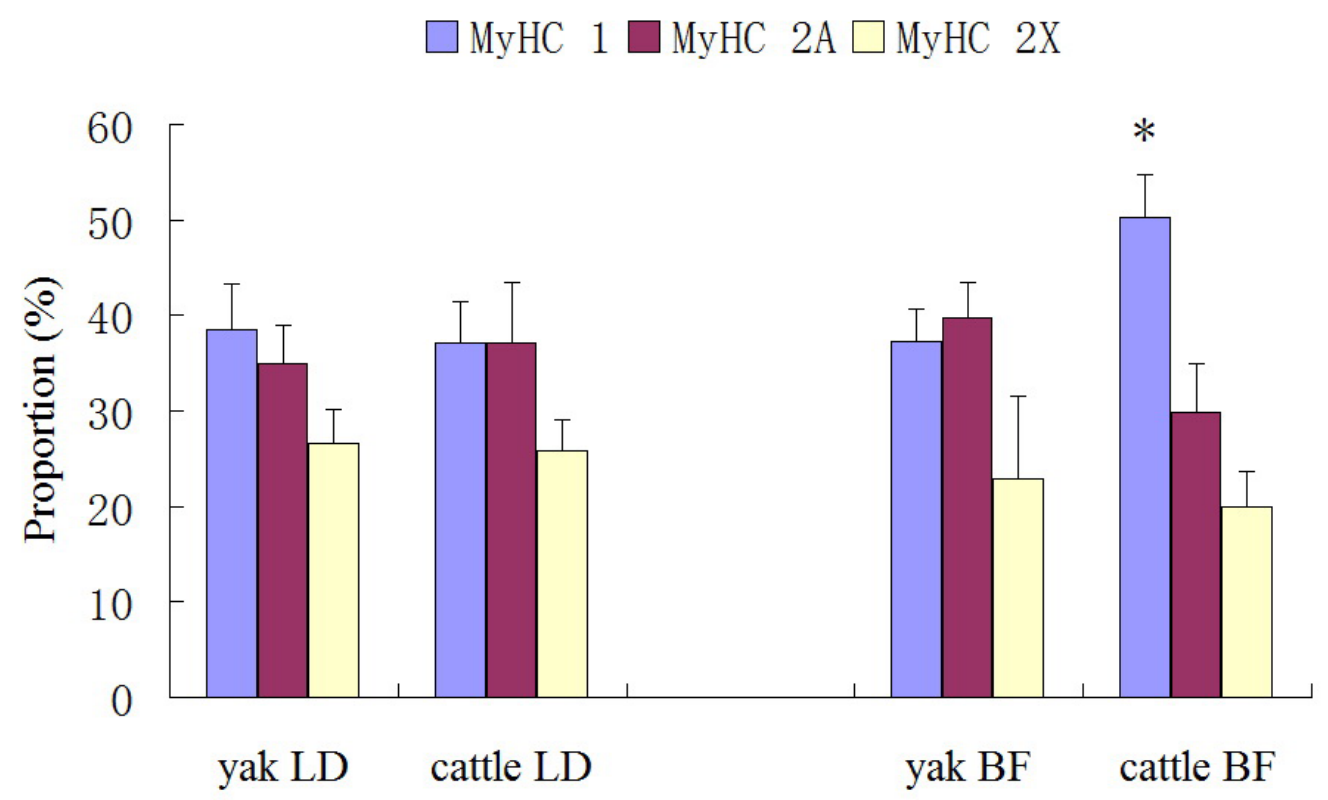

Figure 1. Proportion of $M y H C$ isoforms in yak and bovine muscles. *Indicates that the difference in the proportion of $M y H C$ isoform between yak and Yellow cattle for the same type of muscle is significant at $\mathrm{P}<0.05$. $\mathrm{LD}=$ longissimus dorsi; $\mathrm{BF}=$ biceps femoris.

\section{DISCUSSION}

Yaks are well adapted to the hypoxic Qinghai-Tibetan Plateau. Because of the high sequence similarity ( 98 to 99\%) between yak and Yellow cattle in genes assayed (Zheng et al., 2008; Bai et al., 2010; Zhang et al., 2010), yak may act as a suitable animal model to study the mechanism of hypoxia adaptation. Due to the low oxygen environment, energy supply is an important aspect for studying adaptation in yaks. CPT plays a key role in fatty acid oxidation in mitochondria by translocating long-chain fatty acids from the cytosol to the mitochondrial matrix (Grummer, 1993). The lower CPT mRNA level in biceps femoris of yak compared to Yellow cattle may indicate an attenuated capacity of fatty acid oxidation in yak. This is in accordance with the characteristic of energy metabolism as reported in human muscle adaptation to hypoxia (Hoppeler et al., 2003). A similar tendency was also observed in longissimus dorci of yak and Yellow cattle, although the difference was not significant (Table 2). Our experiment also discovered differences in CPT mRNA level between biceps femoris and longissimus dorsi, which have a different oxidative capacity, in both yak and Yellow cattle; therefore, we suppose that $C P T$ expression is an appropriate marker to evaluate fatty acid oxidation state.

Uncoupling proteins (UCP1, UCP2 and UCP3) are important in regulating cellular energy metabolism and reactive oxygen species production in mitochondria (Rousset et al., 
2004; Azzu et al., 2010). UCP3 is expressed predominantly in skeletal muscle and its exact function remains to be elucidated. UCP3 expression is associated with increases in circling fatty acid and fatty acid oxidation in muscle (Costford et al., 2007), and there is evidence that UCP3 is more involved in fatty acid metabolism than in energy metabolism (for review, see Schrauwen and Hesselink, 2002). In our experiment, yak and bovine muscles shared a similar pattern of $U C P 3$ and $C P T$ mRNA expression (Table 2), suggesting that the lower UCP3 mRNA level in muscles is associated with reduced fatty acid oxidation in yaks relative to Yellow cattle.

The different isoforms of the $M y H C$ protein are the best markers to characterize muscle fiber type diversity. The oxidative and glycolytic capacities differ between muscle fiber types, and oxidative metabolism decreases in the rank order of fiber type I, IIa, IIx, IIb (Lefaucheur et al., 2004; Moreno-Sánchez et al., 2008). Our experiment found that the level of MyHC I mRNA in yak biceps femoris is lower than that of Yellow cattle (Figure 1), suggesting that yak biceps femoris exhibits more glycolytic potential although the activities of HOAD, COX and ICDH in biceps femoris are similar. This may be a result of yaks' adaptation to hypoxia because they live in the highlands where oxygen supply is much lower, compared to Yellow cattle living in low altitude regions. The increased HOAD and COX activities in yak biceps femoris compared to longissimus dorsi should reflect the relatively higher needs for fatty acid oxidation in biceps femoris, and this is consistent with the higher level of $C P T$ in yak biceps femoris compared to longissimus dorsi. Yaks are characterized by active moving in search for grass availability, and thus, biceps femoris needs more energy. In contrast, longissimus dorsi does not need as much movement as biceps femoris and its energy metabolism is relatively lower. Perhaps this can also explain why we did not observe a significant difference in fiber types of longissimus dorsi between yak and Yellow cattle. Taken together, a hypoxic environment may decrease fatty acid oxidation in yak muscle as indicated by muscle $C P T$ and $U C P 3 \mathrm{mRNA}$ levels, and this adaptation may further influence fiber types of yak muscle and possibly meat traits, since muscle properties are associated with its fiber types (Klont et al., 1998; Moreno-Sánchez et al., 2008). Therefore, research on the detailed mechanism of this influence could be helpful in regulating yak meat quality by a genetic or physiological approach.

In conclusion, the present data demonstrate that yak contains significantly lower mRNA levels of $C P T, U C P 3$, and $M y H C 1$ in biceps femoris compared to Yellow cattle, suggesting that yak biceps femoris exhibits lower fatty acid oxidation capacity and more glycolytic metabolic potential.

\section{ACKNOWLEDGMENTS}

Research supported by the National Basic Research Program of China (\#2007CB116204) and the Animal Science Discipline Program of Southwest University for Nationalities (\#2011XWD-S0905).

\section{REFERENCES}

Azzu V, Jastroch M, Divakaruni AS and Brand MD (2010). The regulation and turnover of mitochondrial uncoupling proteins. Biochim. Biophys. Acta 1797: 785-791.

Bai WL, Yin RH, Zheng YC and Ma ZJ (2010). Cloning and molecular characterization of a yak $\alpha$-lactalbumin cDNA from mammary tissue. Livest. Sci. 129: 122-128. 
Bottje WG and Carstens GE (2009). Association of mitochondrial function and feed efficiency in poultry and livestock species. J. Anim. Sci. 87: E48-E63.

Cai L and Wiener G (1995). The Yak. The Regional Office for Asia and the Pacific of the Food and Agriculture Organization of the United Nations. Bangkok, Thailand, 99-101.

Costford SR, Seifert EL, Bezaire V, Gerrits F, et al. (2007). The energetic implications of uncoupling protein-3 in skeletal muscle. Appl. Physiol. Nutr. Metab. 32: 884-894.

Grummer RR (1993). Etiology of lipid-related metabolic disorders in periparturient dairy cows. J. Dairy Sci. 76: $3882-$ 3896.

Hoppeler H, Vogt M, Weibel ER and Fluck M (2003). Response of skeletal muscle mitochondria to hypoxia. Exp. Physiol. 88: 109-119.

Jurie C, Ortigues-Marty I, Picard B, Micol D, et al. (2006). The separate effects of the nature of diet and grazing mobility on metabolic potential of muscles from Charolais steers. Livest. Sci. 104: 182-192.

Klont RE, Brocks L and Eikelenboom G (1998). Muscle fibre type and meat quality. Meat Sci. 49: S219-S229.

Lefaucheur L, Milan D, Ecolan P and Le Callennec C (2004). Myosin heavy chain composition of different skeletal muscles in Large White and Meishan pigs. J. Anim. Sci. 82: 1931-1941.

Livak KJ and Schmittgen TD (2001). Analysis of relative gene expression data using real-time quantitative PCR and the $2^{-\Delta \Delta C t}$ method. Methods 25: 402-408.

Moreno-Sánchez N, Diaz C, Carabano MJ, Rueda J, et al. (2008). A comprehensive characterisation of the fibre composition and properties of a limb (flexor digitorum superficialis, membri thoraci) and a trunk (psoas major) muscle in cattle. BMC Cell Biol. 9: 67.

Rousset S, Alves-Guerra MC, Mozo J, Miroux B, et al. (2004). The biology of mitochondrial uncoupling proteins. Diabetes 53 (Suppl 1): S130-S135.

Schrauwen P and Hesselink M (2002). UCP2 and UCP3 in muscle controlling body metabolism. J. Exp. Biol. 205: 22752285.

Sherman EL, Nkrumah JD, Murdoch BM, Li C, et al. (2008). Polymorphisms and haplotypes in the bovine neuropeptide $\mathrm{Y}$, growth hormone receptor, ghrelin, insulin-like growth factor 2, and uncoupling proteins 2 and 3 genes and their associations with measures of growth, performance, feed efficiency, and carcass merit in beef cattle. J. Anim. Sci. 86: 1-16.

Zhang L, Ma B, Wu J, Fei C, et al. (2010). Cloning and characterization of the yak gene coding for calpastatin and in silico analysis of its putative product. Acta Biochim. Pol. 57: 35-41.

Zheng Y, Si X, He Q, Jin S, et al. (2008). Yak lactate dehydgogenase A4: purification, properties, and cDNA cloning. Biosci. Biotechnol. Biochem. 72: 2448-2451. 